\title{
Medición del gasto turístico en el nivel subnacional: Situr Santander
}

Recibido: 09/11/2016 · Aceptado: 27/03/2017

\author{
Guillermo Rincón Velandia \\ Facultad de Ingeniería Industrial \\ Universidad Pontificia Bolivariana \\ Seccional Bucaramanga, Colombia
}

\section{Resumen}

El Sistema de Información Turística de Santander (Situr Santander) es una experiencia piloto en Colombia, que tiene el propósito esencial de medir el impacto del turismo desde las perspectivas económica, social, cultural y ambiental en el nivel subnacional, información fundamental para la gestión y planificación del destino si se quiere asegurar su sostenibilidad a largo plazo. La medición del turismo como sector económico requiere el estudio de la demanda y la oferta. Por el lado de la demanda, la estimación del gasto realizado por los turistas durante su estancia en un territorio permite saber cómo se distribuyen los ingresos en toda la cadena de valor y el aporte del turismo al desarrollo y crecimiento regional. La estimación del gasto turístico receptor siguió los lineamientos de la Organización Mundial de Turismo y las recomendaciones de InRoute. Los datos se recolectaron mediante una encuesta digital aplicada a una muestra mensual de visitantes contactados inicialmente de forma presencial, facilitando al turista el registro en detalle de cada uno de los gastos efectuados. La metodología utilizada ha sido adoptada por el Ministerio de Comercio, Industria y Turismo para llevar a cabo las mismas mediciones en otros departamentos de Colombia. Los resultados permitieron conocer la composición y magnitud de los gastos de los turistas, además de los ingresos recibidos en cada una de las actividades principales asociadas al turismo.

Palabras clave: Gasto turístico, medición del gasto, impacto económico del turismo.

*Correo electrónico: guillermo.rincon@upb.edu.co 


\title{
Measurement of tourism spending at a subnational level: Situr Santander
}

Recieved: 09/11/2016 · Accepted: 27/03/2017

\author{
Guillermo Rincón Velandia \\ Facultad de Ingeniería Industrial \\ Universidad Pontificia Bolivariana \\ Seccional Bucaramanga, Colombia
}

\begin{abstract}
The Tourist Information System of Santander (Situr Santander) is a pilot experience in Colombia whose essential purpose is to measure the impact of tourism from an economic, social, cultural and environmental perspective at a subnational level. This information is considered essential for the management and planning if it's long-term sustainability wants to be secured. The measurement of tourism as an economic sector requires the study of demand and supply. As for the demand, the estimation of tourist spending during their stay in a territory makes it possible to know the distribution of income throughout the value chain and assess the contribution of tourism to regional development and growth. The estimate of receptor tourist expenditure followed the guidelines of the World Tourism Organization and recommendations of InRoute. Data was collected through an online survey applied to a sample of monthly visitors initially contacted in person, facilitating tourists to register in detail each of the expenses incurred. The methodology has been adopted by the Ministry of Commerce, Industry and Tourism to perform the same measurements in other departments of Colombia. The results allowed knowing the composition and magnitude of tourist spending, plus income received in each of the primary activities associated with tourism.
\end{abstract}

KEY woRDs: Tourist spending, measurement of expenditure, economic impact of tourism.

*E-mail: guillermo.rincon@upb.edu.co 


\section{Introducción}

La carencia de información de la industria del turismo es notable en todas las regiones colombianas. La formulación de planes de desarrollo del turismo por organismos gubernamentales en los departamentos de Colombia podrían orientar con mayor certeza las inversiones en infraestructura y las actividades de promoción como destino turístico, si se tuviera información actualizada del desempeño del sector y las tendencias que se prevén para la industria en el largo plazo. Asimismo, los empresarios contarían con más elementos de juicio para realizar inversiones y adecuar la oferta de productos y servicios a las expectativas de los visitantes, permitiendo estructurar y direccionar adecuadamente sus planes de mercadeo.

El principal reto del Sistema de Información Turística de Santander (Situr Santander) ha sido suministrar información para armonizar la demanda con la oferta, aspecto considerado fundamental para impulsar el desarrollo y crecimiento regional. El conocimiento del perfil y el comportamiento de los visitantes que llegan a un territorio (turismo receptor) y la medición del gasto ayuda a los actores clave de la industria a entender el turismo desde el lado de la demanda, información valiosa para la construcción de una oferta de productos y servicios diferenciados, el diseño e implementación de innovadores programas de promoción del destino y la elección de canales alternativos que faciliten la realización de negocios, fortaleciendo la capacidad de la región para atraer nuevos visitantes y logrando ser más competitiva en los mercados nacionales e internacionales.

El objetivo principal de la medición del impacto económico de las actividades asociadas al turismo en Santander desde el ámbito de la demanda se ha fundamentado en estudiar las características de los flujos de visitantes receptores, medir el gasto y la opinión respecto de sus experiencias de viaje. En este sentido, el proyecto aborda varias preguntas de investigación; específicamente con relación al gasto plantea cuál es el gasto de los visitantes y cómo es su composición teniendo en cuenta los diversos eslabones de la cadena de valor.

Respecto a la medición del gasto turístico receptor que corresponde al realizado por un visitante no residente en la economía de referencia, es importante resaltar que este "hace referencia a la suma pagada por la adquisición de bienes y servicios de consumo y de objetos valiosos, para uso propio o para regalar, 
antes y durante los viajes turísticos. Incluye los gastos incurridos por los propios visitantes, así como los gastos pagados o reembolsados por otros" (World Tourism Organization [unwTo], 2014, p. 35).

\section{Antecedentes}

El turismo es considerado en el mundo uno delos sectores económicos con mayores oportunidades para aportar al producto interno bruto de los países con atractivos suficientes para conquistar visitantes. El crecimiento de la llegada de turistas internacionales en el 2016 (3.9\%) (UNWTo, 2016) permite confirmar que los múltiples ataques terroristas no detienen el interés de realizar viajes turísticos.

La Organización Mundial del Turismo (омт) ha puesto especial énfasis en la medición del impacto que generan las actividades relacionadas con el turismo en el desarrollo y crecimiento de los países. La cuenta satélite de turismo ha cumplido el propósito de analizar en detalle todos los aspectos vinculados con "la demanda de bienes y servicios asociados con la actividad de los visitantes, observar la interfaz operativa con la oferta de dichos bienes y servicios en la economía y describir la manera como esta oferta interactúa con otras actividades económicas” (Naciones Unidas, Organización Mundial del Turismo, Comisión de las Comunidades Europeas y Organización para la Cooperación y el Desarrollo Económicos, 2010, p. iii).

En la última década, la омт ha venido resaltando la importancia de la medición del impacto del turismo desde la perspectiva económica, ambiental, social y cultural en el ámbito regional con el propósito de asegurar la sostenibilidad del turismo a largo plazo. La medición del gasto de los visitantes es uno de los aspectos más relevantes en el estudio del impacto económico del turismo en el nivel subnacional, específicamente por la forma como estos ingresos benefician a todos los eslabones de la cadena de valor y contribuyen a la generación de riqueza en las comunidades involucradas.

Las Naciones Unidas han reconocido a la omT "como la organización adecuada para recoger, analizar, publicar, estandarizar y mejorar las estadísticas de turismo y promover la integración de estas estadísticas en el ámbito del sistema de las Naciones Unidas" (unwto, 2015, p. 6). En este sentido, desde el inicio de los proyectos de investigación relacionados con la medición del turismo, se ha tomado 
como elementos de trabajo los conceptos y las recomendaciones metodológicas publicados en diversos documentos, referencia obligatoria para adaptarlos a las mediciones regionales (subnacional) del turismo.

El documento principal para los lineamientos conceptuales y metodológicos de los estudios implementados es International Recommendations for Tourism Statistics 2008 que "proporciona un marco metodológico amplio para la recolección y compilación de estadísticas de turismo en todos los países, independientemente del nivel de desarrollo de sus sistemas estadísticos" (UNwTo, 2010, p. iii). Las recomendaciones incluidas en Methodological Notes to the Tourism Statistics Database (unwTo, 2015) han sido un soporte muy interesante para definir los datos y los indicadores, buscando armonizarlos con el Compendium of Tourism Statistics publicado por la омт, garantizando la comparabilidad en el nivel mundial.

International Recommendations for Tourism Statistics 2008 Compilation Guide ha sido un documento de apoyo al "proporcionar una mayor clarificación y orientación práctica sobre la utilización de las fuentes y los métodos necesarios para compilar las estadísticas sobre el turismo. La guía está diseñada para apoyar la producción de una alta calidad de un conjunto de datos básicos e indicadores de cada país, y para fortalecer la comparabilidad internacional de las estadísticas de turismo" (unwTo, 2014, p. iii).

La oмт publicó en 2017 el documento Measuring Tourism and Sustainability: A Statistical Insight at Subnational Levels unwTo Guidelines in Line with the un Agenda 2030 on Sustainable Development, en el cual se propondrá la metodología básica para medir el impacto económico, ambiental, social y cultural en el ámbito regional. El Situr Santander ha tomado como referencia los borradores preliminares (unwTo e INRouTe, 2013), adelantándose en el desarrollo de una metodología para medir el turismo, buscando mejorar el conocimiento del impacto de este en el nivel subnacional.

La medición del gasto turístico ha sido abordada desde diferentes facetas (Sainaghi, 2012). En la última década se han planteado diversos métodos de medición en el nivel regional (Frechtling, 2006); todos ellos tratan la misma problemática desde distintas perspectivas, y en general siguen los lineamientos de la omT.

El gasto de los visitantes tiene varios efectos multiplicadores en el territorio que los recibe. Mayor ingreso como consecuencia de incrementos en los flujos de turistas genera dinámica en la economía regional y, por consiguiente, más 
empleo (Frechtling y Horvath, 1999). Igualmente, es importante entender que los recursos destinados por los hogares para viajes turísticos compiten con otros gastos discrecionales (Disegna y Osti, 2016; Crouch et al., 2007), confirmando que la inversión realizada por las regiones para atraer visitantes tiene mucho sentido.

El desarrollo y crecimiento del turismo dependen de su sostenibilidad en el tiempo, asegurando beneficios para todos los actores clave de los destinos (Garrigós-Simón, Galdón-Salvador y Gil-Pechuán, 2015). La medición de la sostenibilidad económica es otra de las líneas de investigación de gran proyección y se fundamenta en el impacto generado por el gasto de los visitantes. En este sentido, los gastos de los turistas tendrán más impacto en la región en la medida en que no se concentren en pocos lugares con atractivos turísticos (Koo, ChengLung y Dwyer, 2012). Este aspecto resulta vital en las políticas y estrategias regionales; el propósito es lograr que el turismo sea una alternativa real para superar cuestiones como la pobreza de regiones remotas y desfavorecidas pero ricas, por ejemplo, en atractivos naturales.

Santander es un departamento ubicado en el oriente de Colombia, posee un valioso patrimonio natural, histórico y cultural, que lo convierte en un destino con atractivos suficientes para cautivar turistas nacionales e internacionales. En la última década se ha mejorado significativamente la infraestructura básica requerida para recibir crecientes flujos de visitantes, y ha sido visible el incremento de la inversión pública y privada, sin embargo, es frecuente el reclamo de la falta de información que permita conocer el impacto de la actividad turística en la economía regional. Como fruto de estas reflexiones nace el Situr Santander (www.sitursantander.co).

\section{Metodología}

Es importante reconocer avances significativos y valiosos en el mundo respecto de la medición del turismo en el nivel subnacional. La International Network on Regional Economics, Mobility and Tourism (INRouTe) (unwTo e INRouTe, 2013), con el apoyo de la Organización Mundial del Turismo, es un magnífico ejemplo y ha sido el referente desde el comienzo del proyecto Situr Santander.

Sin embargo, tomar las características propias de nuestro entorno y dise142 nar procesos de investigación que permitieran adaptar los métodos y procedimientos del ámbito nacional a niveles subnacionales requirió la tarea juiciosa 
de un grupo de investigadores que ha tenido como propósito hacer una correcta identificación de las variables de estudio, examinar la forma de medirlas y seleccionar adecuadamente la población objetivo, el marco muestral, las unidades estadísticas y el tamaño de la muestra. Igualmente, elegir los mejores parámetros para el diseño de la ejecución del trabajo de campo, los sistemas de apoyo y los métodos y mecanismos para el control, así como la ejecución de pruebas piloto, análisis, evaluación y difusión de los resultados. La meta: la construcción de una metodología que sirva de referencia para mediciones similares en otras regiones colombianas.

\section{Diseño del formulario o cuestionario}

La construcción de los cuestionarios tomó como base los conceptos, las indicaciones y las variables incluidas en el manual RIET 2008 (unwTo, 2010), las recomendaciones de Methodological Notes to the Tourism Statistics Database (unwto, 2015) e International Recommendations for Tourism Statistics 2008 Compilation Guide (unwTo, 2014).

La intención de recopilar la mayor cantidad de datos relacionados con el viaje turístico llevó a reconocer la imposibilidad de hacerlo en un único cuestionario y momento. La razón es que el contacto con el visitante se puede realizar en cualquier instante a partir de la fecha de entrada a un territorio. Estos encuentros pueden suceder cuando inicia su visita o ha efectuado parcialmente la visita a los sitios seleccionados o cuando está próximo a salir para el lugar habitual de residencia al final de su viaje. En las dos primeras situaciones no sería posible recolectar por completo los datos mediante una entrevista personal, debido a que la experiencia de viaje no ha terminado y aún es incierto si se cumple el plan de viaje previsto y menos anticipar los gastos que se puedan generar. Si se hace en el momento de salir para el lugar de origen, resultaría muy difícil recopilar la totalidad de los datos solicitados por la poca disposición del encuestado debido el cansancio normal del final de un viaje y el deseo de llegar a su lugar de residencia.

Para dar solución a estas circunstancias y asegurar la captura de los datos requeridos para cumplir los objetivos de la investigación, se tomó la decisión de construir dos cuestionarios que fueran aplicados en momentos diferentes: 
- Momento I: corresponde al momento de encuentro inicial con el visitante; el propósito es recopilar datos básicos y lograr la autorización para enviar un segundo cuestionario para ser diligenciado por internet dos días después de la fecha prevista de la salida de Santander a su lugar habitual de residencia.

- Momento II: corresponde al momento cuando el visitante en su lugar de residencia habitual recibe un mensaje a su cuenta de correo, invitándolo mediante un acceso a diligenciar un cuestionario en formato electrónico. En el cuadro 1 se detallan las partes del cuestionario, el nombre de la pregunta, su objetivo y el número de preguntas.

\section{CuAdRo 1.Estructura del cuestionario electrónico / Momento II}

\begin{tabular}{|c|c|c|c|}
\hline Parte & Nombre & Objetivo & $\begin{array}{l}\text { Núm. de } \\
\text { preguntas }\end{array}$ \\
\hline A & $\begin{array}{l}\text { Características del } \\
\text { visitante }\end{array}$ & $\begin{array}{l}\text { Conocer características } \\
\text { sociodemográficas del visitante }\end{array}$ & 2 \\
\hline $\mathrm{B}$ & $\begin{array}{l}\text { Duración de estancia y } \\
\text { lugares visitados }\end{array}$ & $\begin{array}{l}\text { Estimar la estancia media e } \\
\text { identificar los lugares visitados y } \\
\text { actividades realizadas }\end{array}$ & 5 \\
\hline $\mathrm{C}$ & Transporte utilizado & $\begin{array}{l}\text { Conocer el tipo de transporte para } \\
\text { trasladarse desde el origen y el } \\
\text { utilizado en el destino }\end{array}$ & 2 \\
\hline $\mathrm{D}$ & Viaje en grupo & $\begin{array}{l}\text { Conocer las características y } \\
\text { conformación del grupo de viaje }\end{array}$ & 2 \\
\hline $\mathrm{E}$ & $\begin{array}{l}\text { Gastos de preparación y } \\
\text { duración del viaje }\end{array}$ & $\begin{array}{l}\text { Estimar el gasto medio percápita } \\
\text { clasificado por rubros }\end{array}$ & 10 \\
\hline $\mathrm{F}$ & $\begin{array}{l}\text { Percepción del viaje a } \\
\text { Santander }\end{array}$ & $\begin{array}{l}\text { Conocer la percepción relacionada } \\
\text { con el viaje realizado }\end{array}$ & 7 \\
\hline G & $\begin{array}{l}\text { Uso de medios de } \\
\text { comunicación antes, } \\
\text { durante y después del } \\
\text { viaje turístico }\end{array}$ & $\begin{array}{l}\text { Determinar el nivel de uso de } \\
\text { medios para buscar información o } \\
\text { compartir experiencias }\end{array}$ & 5 \\
\hline
\end{tabular}

Fuente: Elaboración propia. 


\section{Diseño estadístico}

El diseño estadístico buscó la mayor representatividad de la población de estudio con el propósito de garantizar la máxima precisión de los estimadores estadísticos.

- Universo de estudio. Corresponde a las personas que se desplazan de su entorno habitual al departamento de Santander, por una duración inferior a un año, con cualquier finalidad principal (ocio, negocios u otro motivo personal) que no sea ser empleado por una entidad residente en Santander. A estas personas se les denomina visitantes receptores.

- Población objetivo. Visitantes receptores con edad mayor a 15 años. Los visitantes receptores con edad igual o inferior a 15 años se excluyen del estudio basado en el criterio de la responsabilidad de diligenciamiento del cuestionario físico (sitio de entrevista) y el electrónico después de su salida de Santander.

- Marco estadístico. Se define como el conjunto de personas que se encuentran durante el periodo de referencia de la recolección de los datos en los lugares de mayor concentración de visitantes, excluyendo los menores de 15 años. La identificación de las personas que no cumplen con las características de un visitante receptor se hace tomando como base los datos registrados en el cuestionario aplicado en el momento I.

- Definición de variables. Las variables base de la investigación tomaron como referencia las recomendadas en RIET 2008 (unwTo, 2014). Se adicionaron dos grupos de variables que se consideraron relevantes para completar el conocimiento del comportamiento de los flujos de visitantes a Santander. Teniendo en cuenta que la recolección de los datos se realiza en dos momentos, cada cuestionario aborda diferentes grupos de variables (véase cuadro 2).

- Variables para anonimización. Para mantener la reserva y confidencialidad de los datos personales de los participantes del estudio, los microdatos son anonimizados, por esta razón, el teléfono y correo electrónico capturados en la entrevista personal no serán incluidos en la bases de datos de uso público.

- Unidad de observación. Visitante receptor mayor de 15 años. 
CUADRo 2. Variables base del estudio turismo receptor

Cuestionario entrevista personal Momento I

- Características sociodemográficas

- Llegadas por lugar de residencia

- Motivo principal de viaje

- Duración media de la estancia (en noches)

- Tipología del visitante: excursionista o turista

- Tamaño del grupo de viaje

- Composición del grupo de viaje
Cuestionario encuesta electrónica Momento II

- Lugares visitados

- Actividades realizadas durante el viaje

- Alojamiento utilizado

- Medios de transporte para llegar y movilizarse en el destino

- Formas de organización del viaje

- Gasto turístico

- Nivel de satisfacción del viaje y valoración de la experiencia

- Canales de comunicación utilizados por los visitantes antes, durante y después del viaje

Fuente: Elaboración propia.

- Unidad de análisis. Viaje turístico receptor.

- Unidad de muestreo.Grupo de viajeros receptores.

- Periodo de recolección. Mensual.

- Tipo de muestreo. Por las características de la población de estudio, es decir, la imposibilidad de conocer con anticipación el número de integrantes, el diseño muestral propuesto es un diseño no-probabilístico. Para cuidar la confiabilidad y veracidad de los datos, se han desarrollado estrictos protocolos para la selección de la muestra con el fin de mantener procedimientos estandarizados que garanticen la representatividad de la población de estudio y los resultados obtenidos puedan servir para ser estimaciones del impacto del turismo en la economía regional.

- Definición del tamaño de la muestra. Con objeto de lograr una adecuada desagregación geográfica de los lugares identificados como los mejores para entrevistar a los visitantes, cada uno se considera como una subpoblación de estudio. Se calculó una muestra de grupos de viaje para cada lugar 
seleccionado, utilizando la fórmula para una población infinita, con una precisión esperada no superior a un error estándar relativo de $5 \%$, nivel de confianza de $95 \%$ y una varianza máxima para una distribución de proporciones.

- Es importante resaltar que las muestras no son iguales para cada una de las subpoblaciones, debido a la variabilidad del número de visitantes, lo que significa un ajuste para mantener la representatividad de cada elemento de la muestra; además se deben tener en cuenta los ciclos de estacionalidad que caracterizan a la industria. En el cuadro 3 se presenta la distribución de la muestra aplicada de junio de 2015 a mayo de 2016.

\section{CuAdro 3. Distribución de la muestra en Santander}

\begin{tabular}{|c|c|c|c|c|c|c|c|c|c|c|c|c|c|}
\hline & Total & & & & 2015 & & & & & & 2016 & & \\
\hline & & Jun & Jul & Ago & Sep & Oct & Nov & Dic & Ene & Feb & Mar & Abr & May \\
\hline $\begin{array}{l}\text { Bucaramanga } \\
\text { Acualogo }\end{array}$ & 2225 & 300 & 300 & 100 & 100 & 125 & 100 & 300 & 300 & 100 & 100 & 300 & 100 \\
\hline $\begin{array}{l}\text { Bucaramanga } \\
\text { aeropuerto }\end{array}$ & 4800 & 400 & 400 & 400 & 400 & 400 & 400 & 400 & 400 & 400 & 400 & 400 & 400 \\
\hline $\begin{array}{l}\text { Bucaramanga } \\
\text { terminal terrestre }\end{array}$ & 4800 & 400 & 400 & 400 & 400 & 400 & 400 & 400 & 400 & 400 & 400 & 400 & 400 \\
\hline Cerro del Santísimo & 3250 & 300 & 300 & 250 & 250 & 250 & 250 & 300 & 300 & 250 & 250 & 300 & 250 \\
\hline $\begin{array}{l}\text { Parque Nacional } \\
\text { del Chicamocha }\end{array}$ & 3750 & 400 & 400 & 250 & 250 & 250 & 250 & 400 & 400 & 250 & 250 & 400 & 250 \\
\hline $\begin{array}{l}\text { Parque Gallineral } \\
\text { San Gil }\end{array}$ & 2800 & 350 & 350 & 150 & 150 & 150 & 150 & 350 & 350 & 150 & 150 & 350 & 150 \\
\hline Barichara & 2375 & 300 & 300 & 125 & 125 & 125 & 125 & 300 & 300 & 125 & 125 & 300 & 125 \\
\hline $\begin{array}{l}\text { Muestra de grupo } \\
\text { de viajes }\end{array}$ & 24000 & 2450 & 2450 & 1675 & 1675 & 1700 & 1675 & 2450 & 2450 & 1675 & 1675 & 2450 & 1675 \\
\hline $\begin{array}{l}\text { Estimación viajeros } \\
\text { entrevistados* }\end{array}$ & 43200 & 4410 & 4410 & 3015 & 3015 & 3060 & 3015 & 4410 & 4410 & 3015 & 3015 & 4410 & 3015 \\
\hline $\begin{array}{l}\text { Estimación de } \\
\text { respuesta para la } \\
\text { encuesta electrónica }\end{array}$ & 5600 & 600 & 600 & 400 & 400 & 400 & 400 & 600 & 600 & 400 & 400 & 400 & 400 \\
\hline
\end{tabular}

* Por estudio realizado en promedio se entrevistan entre 1 y 2 visitantes por grupo de viaje 


\section{Resultados}

El impacto económico del turismo depende del gasto que realizan los visitantes durante su estancia en un destino. Los beneficiados, todos los eslabones de la cadena de valor.

Las mediciones del gasto turístico permiten visualizar el impacto que genera el turismo a la economía regional por el aporte a las siguientes actividades empresariales:

- Transporte interdepartamental de pasajeros

- Transporte intermunicipal de pasajeros (interior del territorio)

- Alquiler de vehículos

- Compra de combustibles

- Servicios de alojamiento

- Alimentos y bebidas

- Actividades recreativas, culturales y deportivas

- Artesanías (incluye recuerdos, ropa y calzado artesanal)

- Objetos valiosos (joyas y obras de arte)

- Bienes de consumo duradero (ropa, calzado, implementos...)

- Asistencia a conferencias, seminarios, congresos, ferias comerciales, etcétera

- Cursos/talleres de enseñanza

- Servicios médicos (incluye cirugías estéticas)

- Otros gastos del viaje

Para medir el gasto de los visitantes fue necesario solicitar a los encuestados una descripción en detalle de las compras efectuadas, determinando el número de personas que benefició e identificando cuáles se llevaron a cabo con sus propios recursos o de terceros. Igualmente, se tuvo en cuenta si los gastos realizados correspondían a la compra de paquetes turísticos. En estos casos, también se requirieron los gastos adicionales efectuados. Para los visitantes extranjeros, los datos de gastos se solicitaron en pesos colombianos, excepto los pagos de transporte internacional que podían ser registrados en la moneda en la que se realizaron. 


\section{Gasto medio turismo receptor}

Se calcula tomando el total de gastos reportados por los visitantes en cada rubro y se divide en la sumatoria de las personas que viajaron y pagaron. De junio de 2015 a enero de 2016 se estima que un visitante en promedio gastó 174 dólares durante su permanencia en Santander. Se observa que en los meses de temporada alta (junio y enero) este valor es superior en $7 \%$, mientras que en temporada baja puede disminuir hasta $14 \%$. Si el gasto medio se divide por el número de noches registrados durante su estancia, se tiene el gasto medio por día. Un visitante en Santander gasta diariamente en promedio 49.6 dólares (véase figura 1).

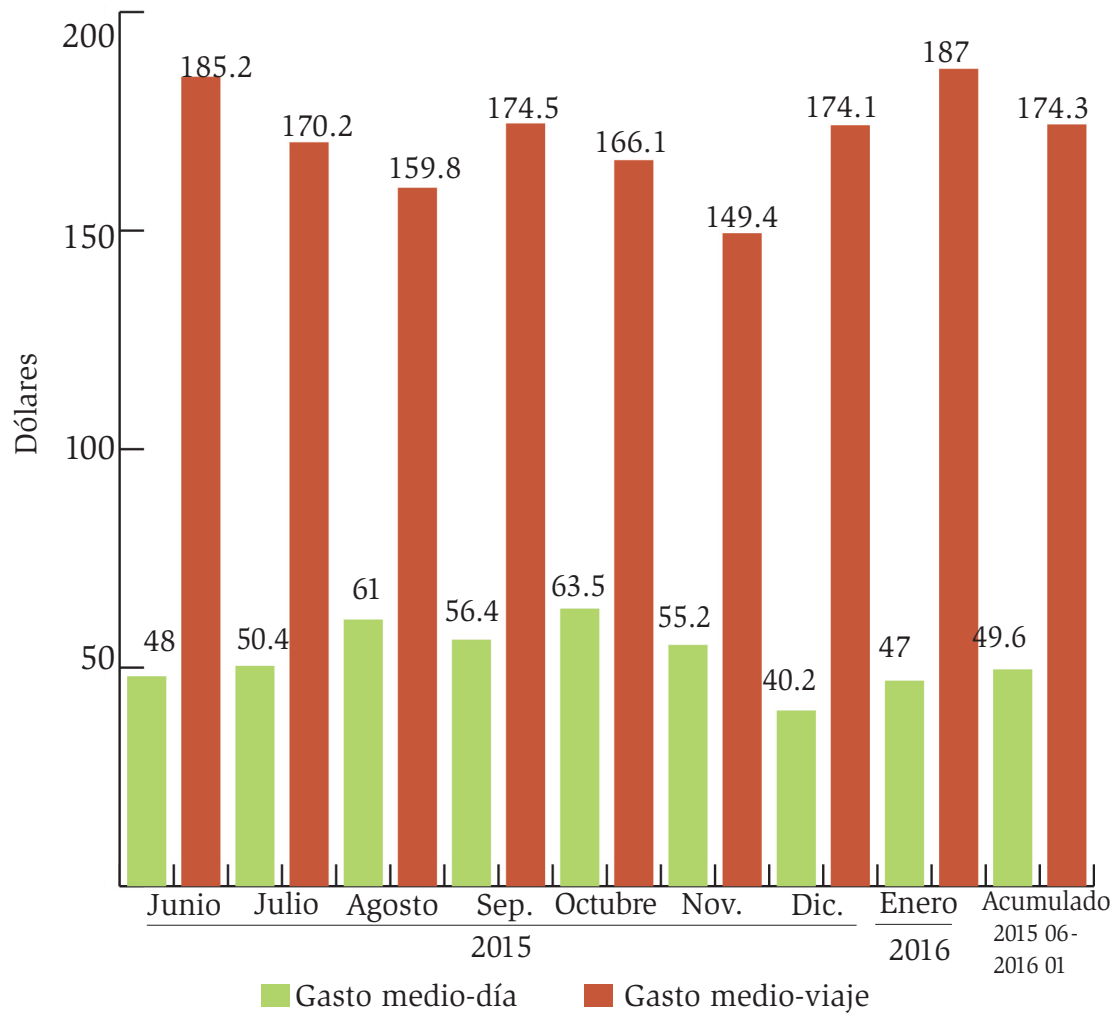

Notas: Entrevistados 2371 visitantes

Un dólar equivale a \$3 069 pesos colombianos (mayo 2016).

Fuente: Situr Santander Colombia.

FiguRa 1. Estimación del gasto medio turístico receptor 
Los cuatro gastos más comunes de los visitantes receptores corresponden a los de alimentos y bebidas (75 \% de los grupos de viaje reportó este gasto); el pago por disfrutar actividades recreativas, culturales y deportivas (62\%); el servicio de alojamiento (51\%); la compra de combustibles (46\%) y artesanías (46\%). Uno de cada cuatro grupos de viaje reportó pagos en transporte intermunicipal $(26 \%)$ e interdepartamental $(26 \%)$ y compra de combustibles $(21 \%)$. En el resto de rubros, menos de $2 \%$ registró gastos (véase figura 2).

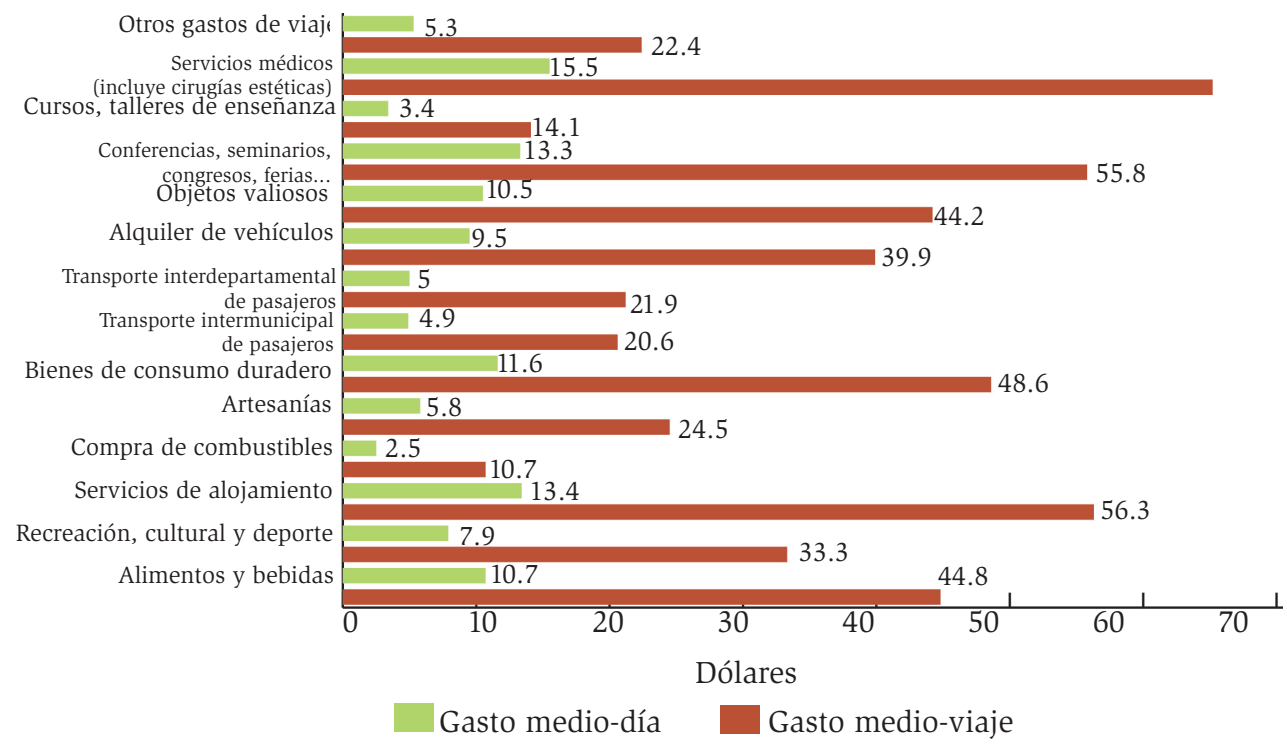

Nota: Entrevistados 2371 visitantes.

Un dólar equivale a \$ 3069 pesos colombianos (mayo 2016).

Fuente: Situr Santander Colombia.

FiguRa 2. Composición del gasto medio turístico receptor 


\section{Composición del gasto turístico en Santander}

En general, alrededor de la mitad del gasto que hacen los visitantes en un destino tiene que ver con dos servicios básicos: la compra de alimentos y bebidas (28\%) y el pago por el alojamiento (25\%) (véase figura 3).

Por otro lado, $18 \%$ de los gastos se invierten en la compra de entradas para observar o participar en actividades recreativas (entrada a parques temáticos), culturales (teatro) y deportivas (práctica de deportes extremos).

Durante el viaje, los turistas adquieren productos como artesanías (8\%) o bienes duraderos (7\%) comprados en centros comerciales o sitios emblemáticos en las ciudades o municipios visitados.

Los gastos de transporte municipal (3\%) o interdepartamental (3.4\%), junto con la compra de combustibles, representan $11.4 \%$ del valor total. El resto de gastos tiene una participación poco representativa.

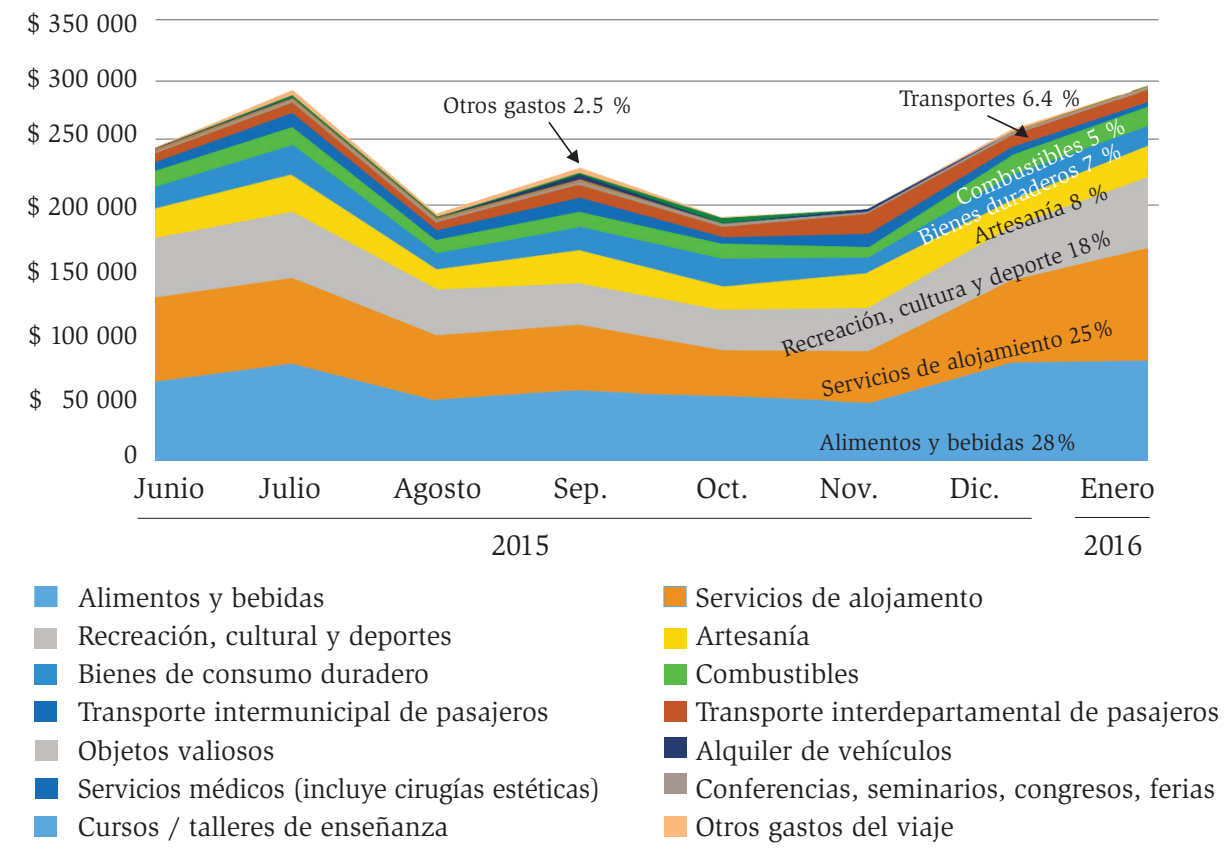

Nota: Entrevistados: 2371 visitantes

Fuente: Situr Santander Colombia

Figura 3. Composición del gasto de los visitantes a Santander, Colombia 


\section{Gasto medio per cápita}

Se calcula tomando el total de gastos reportados por los visitantes en cada rubro y se divide en la sumatoria de las personas que viajaron y pagaron y las personas que viajaron y no pagaron. De junio de 2015 a enero de 2016 se estima que los visitantes a Santander per cápita gastaron en promedio 81 dólares, notándose que en temporada alta sube hasta $19 \%$, mientras que en temporada baja disminuye hasta $22 \%$. Si el gasto medio per cápita se divide por el número de noches de estancia, se tiene que un visitante en Santander gasta per cápita en un día un promedio de 19 dólares (véase figura 4).

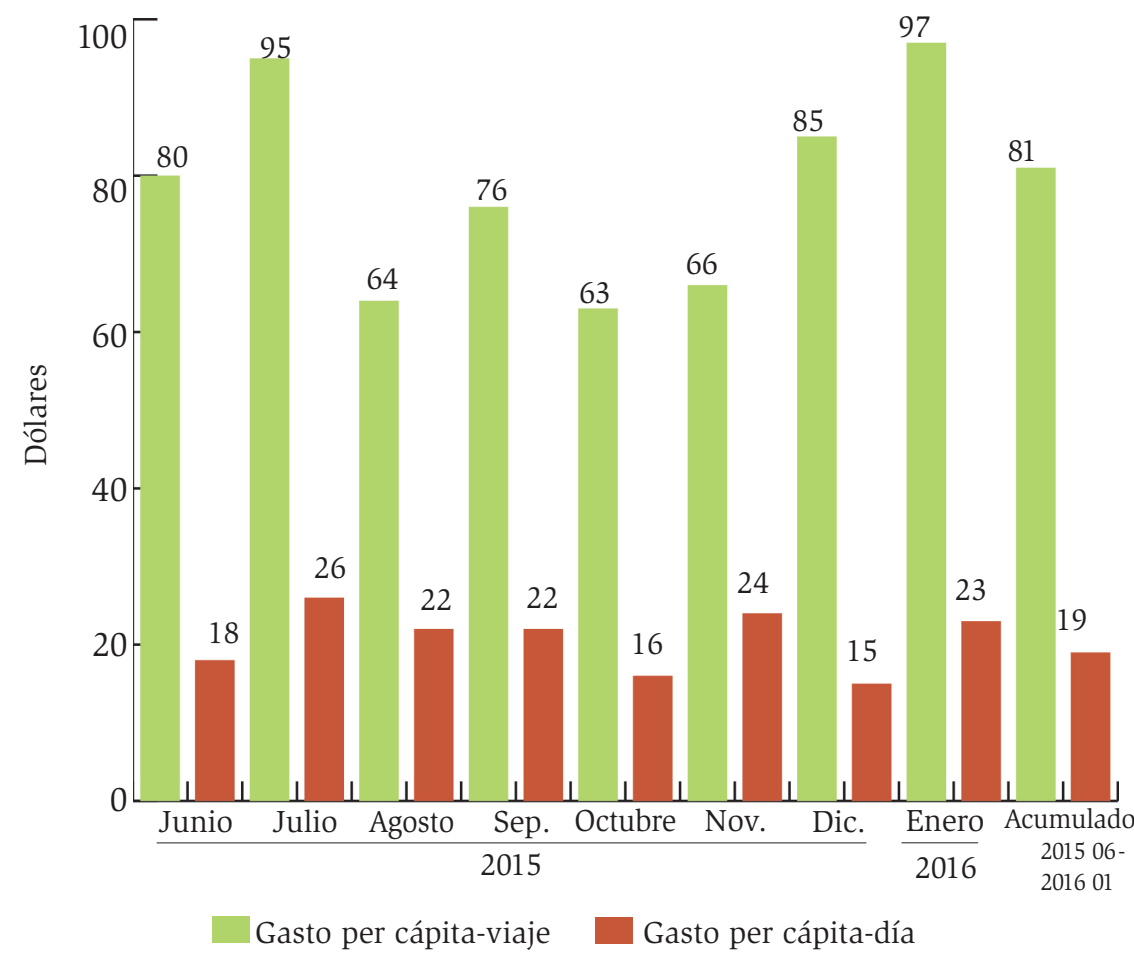

Nota: Entrevistados 2371 visitantes.

Un dólar equivale a \$3069 pesos colombianos (mayo 2016).

Fuente: Situr Santander Colombia.

FiguRa 4. Estimación del gasto per cápita generado por los visitantes 
La estimación del gasto per cápita y del número de visitantes que arriban a Santander permite realizar estimaciones del ingreso promedio que percibe la región como consecuencia de la llegada de turistas. Los ingresos recibidos por Santander de junio de 2015 a enero de 2016 suman 65.1 millones de dólares, lo que significa un promedio mensual de 7.69 millones de dólares de ingresos. Se destacan los meses de temporada alta, como diciembre de 2015 y enero de 2016, que en conjunto participan de $38 \%$ del total de los ingresos. Esta circunstancia resalta los cambios bruscos que se generan por la estacionalidad (véase figura 5).

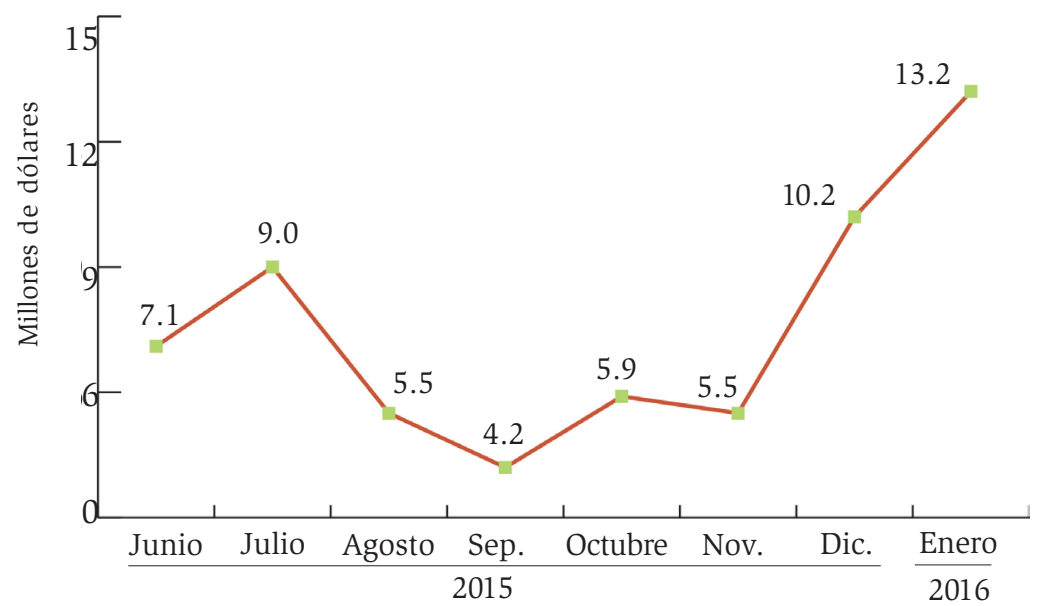

Ingresos generados por turistas \$65.1 millones de dólares (Junio 2015 a enero 2016)

Nota: Un dólar equivale a \$3069 pesos colombianos (mayo 2016).

Fuente: Situr Santander Colombia.

FiguRa 5. Estimación de los ingresos generados por la llegada de turistas a Santander

El turismo es una actividad que genera ingresos a múltiples actividades que intervienen directa o indirectamente en el ofrecimiento de bienes y servicios con el propósito de dar respuesta a las necesidades y problemas que deben resolver los turistas cuando visitan un destino (véase figura 6).

Resulta notable que $71 \%$ de los 65.1 millones de dólares recibidos de junio de 2015 a enero de 2016 se reparte en tres actividades fundamentales durante la permanencia de los grupos de viaje en Santander: suministro de alimentos y 
bebidas, servicios de alojamiento y el pago para disfrutar actividades culturales, recreativas o deportivas. Estos ingresos a su vez cubren el pago de los insumos y el capital humano requerido, lo cual implica que muchas otras actividades se vean beneficiadas y especialmente las familias de la región, que ven en el turismo una alternativa de empleo.

Las compras de productos de consumo duradero y artesanías realizadas por los grupos de viaje durante la permanencia en Santander también tienen importancia, sobre todo aquellos fabricados por microempresarios de la región. Las compras de los visitantes en este tipo de bienes participan de $15 \%$ de los ingresos recibidos por la actividad turística.

La compra de combustibles y el pago de los servicios de transporte generan ingresos por valor de 6.9 millones de dólares y representan $11 \%$ de total del gasto de los visitantes.

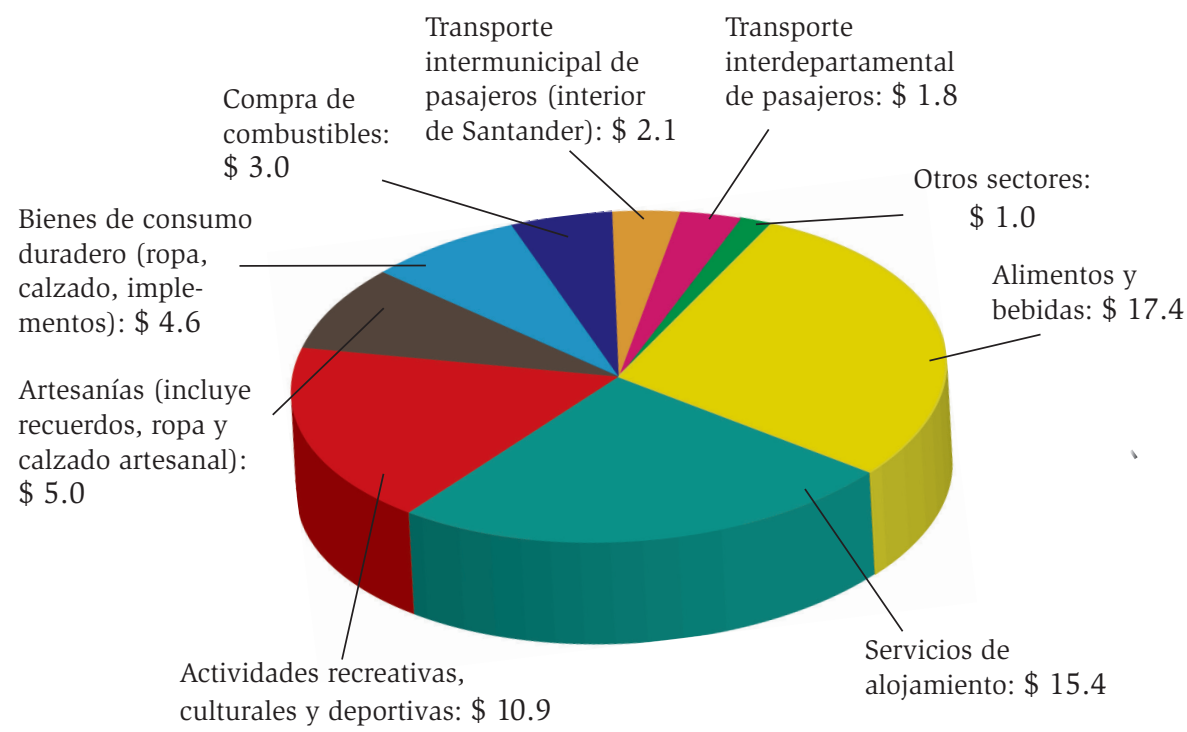

Millones de dólares

Nota: Un dólar equivale a \$ 3069 pesos colombianos.

Fuente: Situr Santander Colombia. 


\section{Discusión}

La falta de información había sido tradicionalmente una de las falencias más destacadas en la gestión y planificación de los destinos con vocación turística. La puesta en operación del Situr Santander ha logrado crear la cultura de la medición y resaltar la utilidad de la información en la toma de decisiones.

Los procesos de investigación orientados por el Situr Santander relacionados con la medición de las características de los turistas y del gasto receptor son considerados un gran aporte a la región, al tener la oportunidad de conocer el perfil de los visitantes y el nivel de ingresos generado en los principales eslabones de la cadena de valor.

Santander es la primera región en Colombia que hace una medición de los gastos vinculados con el turismo receptor. Los datos obtenidos no tienen por ahora punto de contraste, razón por la cual se convierten en una referencia para otras regiones que ya emprendieron estas mediciones con la misma metodología. La desagregación permitirá hacer comparaciones por variables, como residencia habitual y tipo de alojamiento.

En la esfera internacional, países como España, Australia, Austria, Italia, entre otros, presentan avances interesantes en la medición del gasto turístico en el nivel subnacional. En América Latina, naciones como México, Argentina, Brasil, Republica Dominicana, por nombrar algunas, también realizan mediciones similares en el ámbito regional, sin embargo, las condiciones de cada territorio hacen difícil su comparación. Particularmente, Santander es una región en la zona andina localizada en el nororiente de Colombia, $94 \%$ de los visitantes no residentes proviene de otras regiones colombianas y solo $6 \%$ son turistas internacionales. Esto determina patrones de gastos muy diferentes, si se compara con regiones ubicadas en zonas costeras donde el turismo internacional es más importante.

La medición del gasto turístico ha permitido conocer el aporte del turismo a la economía de Santander, resaltando el impacto que tiene la adquisición de bienes y servicios por parte de los visitantes durante un viaje turístico y la forma como genera ingresos para diversas actividades que directa o indirectamente intervienen para hacer realidad una experiencia gratificante. Este hecho ha sido muy valorado por las empresas vinculadas con la industria del turismo, en especial por comprender la contribución que hace este sector al desarrollo 
y crecimiento regional, circunstancia que motiva la asociatividad, condición necesaria para ser más competitivos como destino en los mercados nacional e internacional.

Desglosar el volumen de ingresos generados por los turistas en cada eslabón de la cadena de valor resulta un ejercicio muy útil para convencer a los empresarios de la importancia de la innovación y la inversión para asegurar la sostenibilidad del sector a largo plazo. Los empresarios ya entienden que para motivar a los turistas e incrementar el gasto se requiere el ofrecimiento de productos y servicios diferenciados, es decir, propuestas de valor atractivas con precios adecuados.

Asimismo, se logró que los organismos gubernamentales conozcan los beneficios generados por las inversiones realizadas en la infraestructura básica requerida por los turistas, permitiendo además impulsar el desarrollo de nuevas obras, lo cual consolida al turismo como alternativa para fortalecer los buenos indicadores de crecimiento económico y desarrollo que tradicionalmente ha tenido Santander.

La medición de los ingresos producidos por los visitantes también ha servido para convencer a las comunidades involucradas en lugares con vocación turística de ver al turismo como una alternativa de empleo para sus familias, un medio para mejorar la calidad de vida y un generador de oportunidades para fortalecer las empresas existentes o crear nuevas que den respuesta a las necesidades y problemas de los visitantes. El solo hecho de conocer los ingresos recibidos en un municipio por la llegada de turistas ha concientizado a los habitantes de su responsabilidad para cuidar el patrimonio natural, histórico y cultural, reconociendo al turismo como una alternativa real para superar sus problemas estructurales y alcanzar niveles más altos de bienestar.

Están comprobados los múltiples beneficios para una región derivados de la medición del gasto; por esta razón, durante la construcción de los instrumentos y procesos de medición, ha sido cuidadosamente planeado el proceso de recopilación de este tipo de datos con el fin de vencer los problemas de olvido y precisión respecto a la magnitud de los gastos realizados por los visitantes durante el viaje y los asociados a la disposición de suministrarlos.

La experiencia de los procesos implementados mostró que los datos obtenidos presentan tendencias estadísticamente consistentes y razonables a las 
características de los flujos de visitantes que llegan. Aplicar esta misma metodología en otras regiones colombianas refinará la propuesta inicial y se podrá estandarizar con el propósito de ser compartida en otras que inician el proceso de medición; además, es referencia para procesos similares en otros países.

\section{Conclusión}

La medición de las características de los flujos de visitantes y específicamente la estimación del gasto turístico es información fundamental para lograr articular las políticas gubernamentales, la iniciativa privada y la voluntad de las comunidades asociadas a los territorios con atractivos con valor, permitiendo que el turismo realmente sea una alternativa para mejorar la calidad de vida de la población nativa y se convierta en un sector que aporte al desarrollo y crecimiento regionales, por el significativo impacto económico que genera en cada eslabón de la cadena de valor, fortaleciendo el tejido empresarial y propiciando la innovación para la sostenibilidad, la inversión y la creación de nuevos puestos de trabajo.

\section{Fuentes consultadas}

Crouch, G. I., Oppewal, H., Huybers, T., Dolnicar, S., Louviere, J. J. y Devinney, T. (2007). Discretionary expenditure and tourism consumption: Insights from a choice experiment. Journal of Travel Research, 45, 247258.

Disegna, M. y Osti, L. (2016). Tourists' expenditure behaviour: The influence of satisfaction and the dependence of spending categories. Tourism Economics, 22(1), 5-30.

Frechtling, D. C. (2006). An assessment of visitor expenditure methods and models. Journal of Travel Research, XX, 1-10.

Frechtling, D. C. y Horvath, E. (1999). Estimating the multiplier effects of tourism expenditures on a local economy through a regional input-output. Journal of Travel Research, 37(4), 324-332.

Garrigós-Simón, F. J., Galdón-Salvador, J. L. y Gil-Pechuán, I. (2015). The economic sustainability of tourism growth through leakage calculation. Tourism Economics, 21, 721-739. 
Koo, T. T. R., ChengLung, W. y Dwyer, L. (2012). Dispersal of visitors within destinations: Descriptive measures and underlying drivers. Tourism Management, 33(5), 1209-1219.

Naciones Unidas, Organización Mundial del Turismo, Comisión de las Comunidades Europeas y Organización para la Cooperación y el Desarrollo Económicos. (2010). Cuenta satélite de turismo: Recomendaciones sobre el marco conceptual, 2008. Madrid: Naciones Unidas. Recuperado de http://unstats.un.org/unsd/publication/Seriesf/SeriesF_80rev1s.pdf [2015, 5 de julio].

Sainaghi, R. (2012). Tourist expenditures: The state of the art. An International Journal of Tourism and Hospitality Research, 23, 217-233.

World Tourism Organization (unwTo). (2010). International Recommendations for Tourism Statistics. Madrid: Autor. Recuperado de http://unstats. un.org/unsd/publication/SeriesM/Seriesm_83rev1s.pdf [2015, 20 de julio].

World Tourism Organization (unwTo). (2014). International Recommendations for Tourism Statistics 2008 Compilation Guide. Madrid: Autor. Recuperado de http://dtxtq4w60xqpw.cloudfront.net/sites/all/files/ docpdf/irtscg.pdf [2015, 10 de junio].

World Tourism Organization (unwTo). (2015). Methodological Notes to the Tourism Statistics Database. Madrid: Autor. Recuperado de http://dtxtq4w60xqpw.cloudfront.net/sites/all/files/pdf/2015_metho_notes_ sp.pdf [2015, 15 de julio].

World Tourism Organization (unwTo). (2016). International tourism continues to grow above average in the first four months of 2016. Madrid: Autor. Recuperado de http://media.unwto.org/press-release/2016-07-19/ international-tourism-continues-grow-above-average-first-fourmonths-2016 [2016, 12 de julio].

World Tourism Organization (unwTo) e International Network on Regional Economics, Mobility and Tourism (INRouTe). (2013). A Closer Look at Tourism: Sub-national Measurement and Analysis - Towards a Set of UNWTO Guidelines. Madrid: Autores. Recuperado de http://www.e-unwto.org/ doi/pdf/10.18111/9789284414963 [2015, 20 de julio]. 